\title{
Design and Implementation of a College Logistics Repair Management Platform
}

\author{
Xue-Feng Xiang, Ye Du, Pei-Yuan Li, Tian-Tian Zhang \\ School of Computer and Information Technology, Beijing Jiaotong University, Beijing, China \\ E-mail: \{xfxiang, ydu, pyli, ttzhang $\} @$ bjtu.edu.cn
}

\begin{abstract}
The repair business, as an important business link of college logistics, plays an indispensable role in college basic assurance task. The college logistics repair platform is also the important part of the university information construction. Based on the analysis of demands of the repair business, the paper gives a detailed introduction of the architecture of the repair management platform. Then we analyze the business process specifically and realize the main function of the platform. Experimental results show that the platform has strong reliability and practicability.
\end{abstract}

Keywords- university information construction; repair business; management platform

\section{INTRODUCTION}

With the continuous development of higher education in our country, information has become an important means to carry out the work in colleges and universities. Colleges and universities are combined with their own development needs, to carry out a wide range of information construction. With the development of information construction in Colleges and universities, the operational efficiency and service levels have been significantly improved. But in this process, there are also many problems and challenges.

College logistics, as the foundation of the school business, shoulders the important task for providing the whole school students and teachers with basic life support. Logistics information construction has also become an important link and basis of university information work. In recent years, our school actively explores the logistics information work, a lot of work has been carried out in the aspects of information system construction, smart campus, smart classrooms, energy efficiency and so on. We accumulated a wealth of experience in information technology and also found a lot of problems in the process of information construction.

Maintenance service is the most important in the college logistics, its service and efficiency level directly affects the vital interests of the majority of teachers and students, related to the development and stability of the school. Repair management system, as an important part of the logistics information system, its design, development, construction, operation and maintenance is directly related to the level of university logistics service and how teachers and students feel. Therefore, the construction of a highly efficient, highquality repair management system is an important and challenging thing.

\section{REQUIREMENT ANALYSIS}

The construction of college logistics repair platform, as a basic link of University Information construction, its design and construction should not be separated from the university information construction itself. It should be based on the overall construction of university information. Planning and designing the information system in a systematic way, and make it become a part of the whole university information system. Therefore, in the design and construction of college logistics repair platform, the following principles should be followed:

1) Extendibility

College Logistics repair platform should follow a unified standard, modeling the information system data according to the unified data standard of the school and the enterpriseclass unified data model. Making the necessary data interface and dealing well with other business system in the field of data and business relationship. Classification and coding of data should comply with the existing national standards and industry standards and local standards, and fully consider the future expansion and upgrading needs of the system.

2) Sharing

College Logistics repair platform is corresponding to independent business field, taking system security and maintenance requirements into account. In the construction, from the application point of view should follow the principle of independence. System deployment, operation and maintenance should be independent with other information systems as much as possible. At the same time taking the overall requirements of the school information into account, designing information interaction mechanism from the data layer. Realizing the import of the external data and export of internal data, so as to form a loose coupling mechanism of business independence and information sharing.

3) Availability

College Logistics repair platform as the basic platform of university logistics service, is facing all the students and staff of the school directly. The functionality and usability of the system directly affect the user experience. Therefore, in the development of the platform should fully consider the needs of users. Designing system from the point of view of user convenience, achieve the goal of operation stable, service flexible, response fast.

\section{DESIGN AND IMPLEMENT OF THE SYSTEM}

\section{A. System design}

Take the author's University as an example, logistics repair business mainly includes: repair acceptance, dispatching, charging and evaluation review. The business process is shown in Figure 1. 


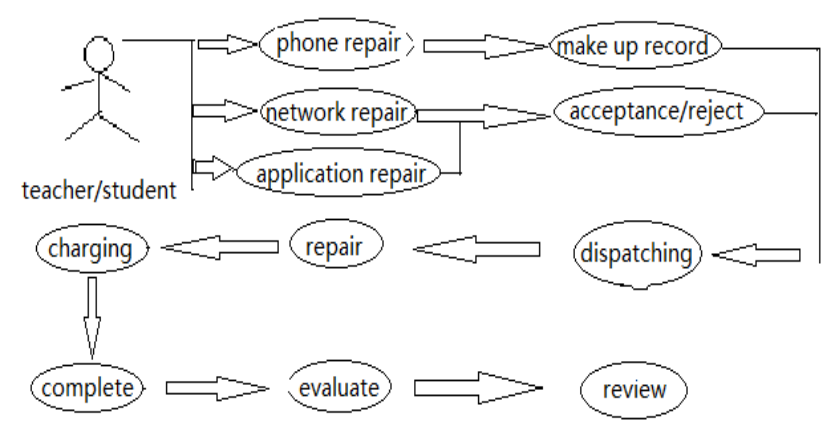

Figure 1. College Logistics repair platform business process

In order to provide user quick service, when designing the college logistics repair platform fully consider to use existing high speed campus network environment. Using $\mathrm{B} / \mathrm{S}$ architecture and building platform's main application based on SSH architecture of JAVA. At the same time in order to facilitate users to quickly ask for repair, platform uses mobile Internet technology. The repair service client based on mobile terminal has been developed. The overall system deployment architecture diagram is shown in Figure 2 .

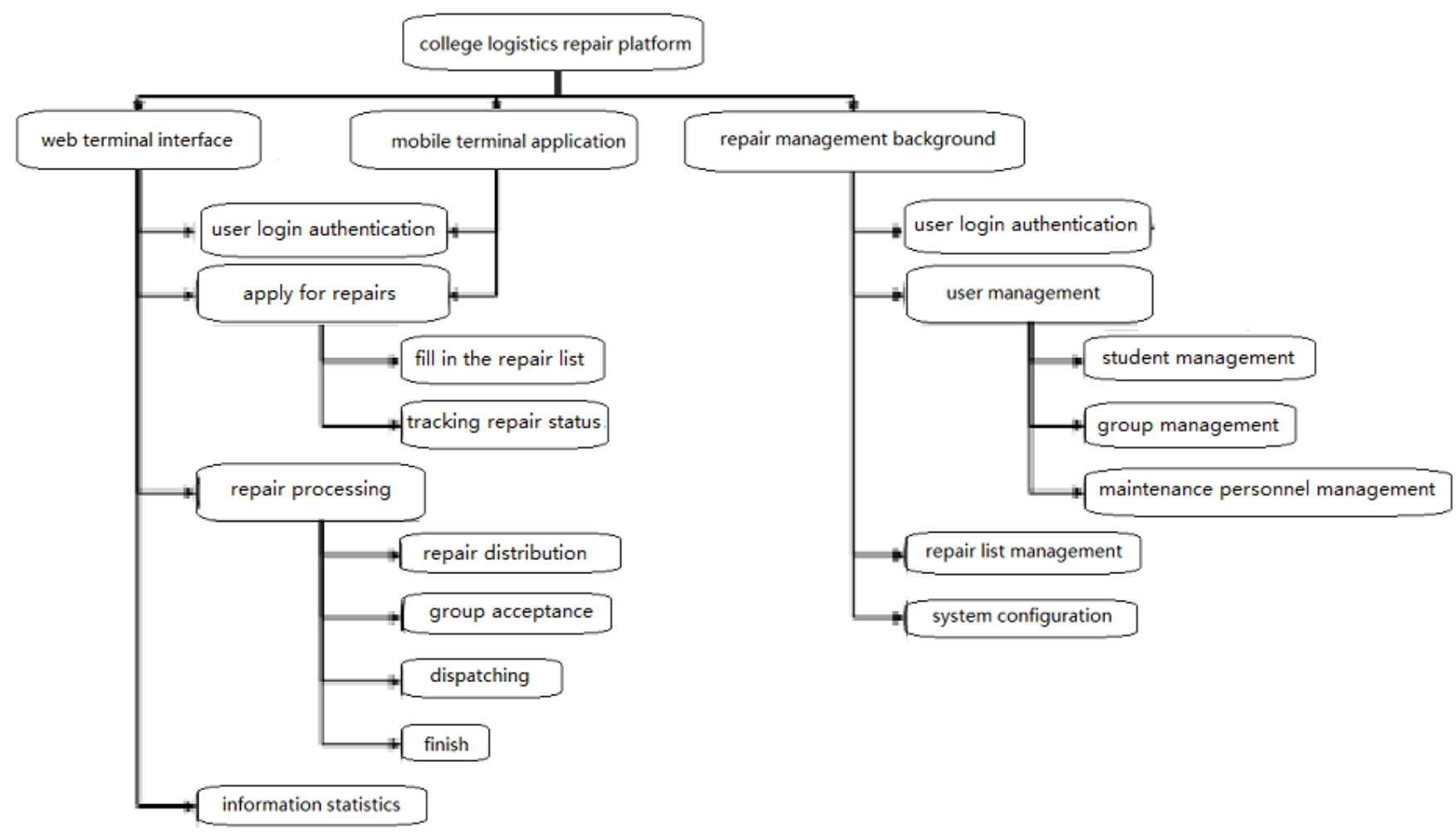

Figure 3. College logistics repair platform function framework

- Repair service interface: is mainly to realize accepting the orders and dispatching. Its intended users include students, teachers and groups two categories. Students

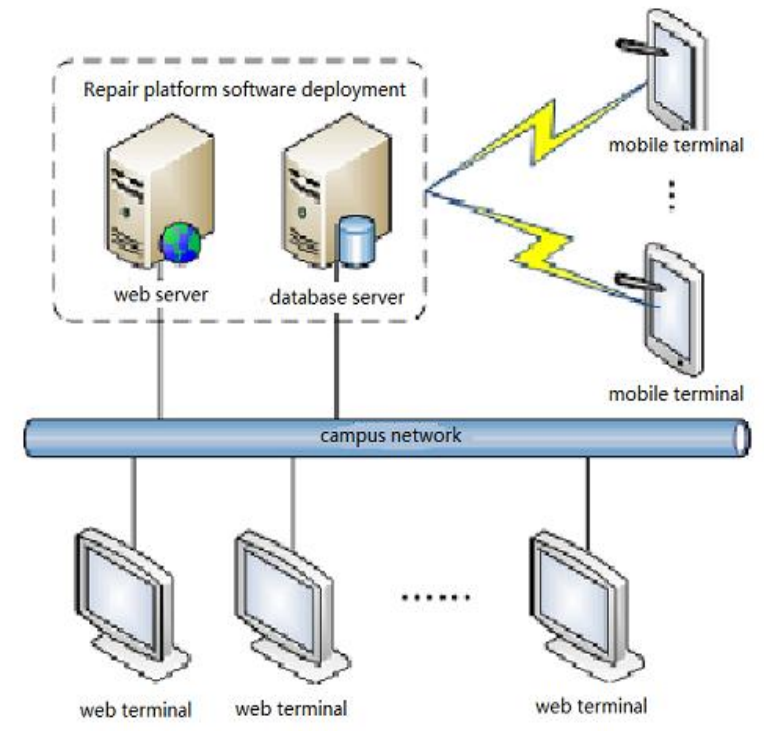

Figure 2. College logistics repair platform system architecture

Platform software is mainly divided into three parts: repair service interface, mobile terminal application and platform management background. The overall functional system is shown in Figure 3. 
- Mobile terminal application: Make full use of mobile internet technology. It mainly aims at students and teachers, and realizes repair task rapid reporting.

- Platform management background: Main functions include system basic data maintenance, system configuration, student and teacher information import, repair list management and so on.

In order to merge the repair platform and the whole school information, the platform fully consider data integration requirements, and it achieves data sharing with data system, MIS and equipment management system from data layer. Meanwhile, repair platform docked with school's MIS, realizing uniform identity authentication and single sign-on. As shown in Figure 4.

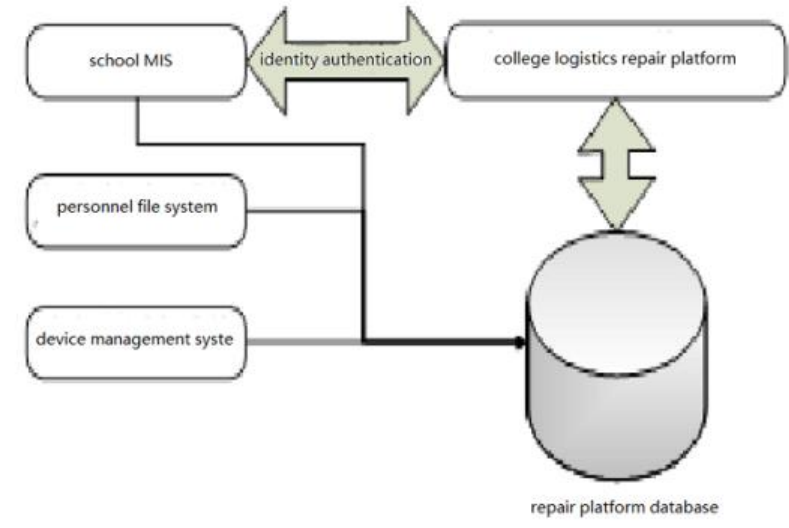

Figure 4. College logistics repair platform docked with external system

\section{B. System implementation}

College logistics repair platform uses $\mathrm{B} / \mathrm{S}$ architecture and SSH architecture of JAVA. The whole program is divided into 3 levels as shown in Figure 5. Among them, the presentation layer is responsible for the display of data and the interaction with the user, mainly realized by Servlet, JSP and so on; Persistence layer is responsible for interaction with the database, to achieve data writing and query, mainly realized by Hibernate; Business layer is responsible for data processing, to achieve all kinds of business logic, mainly realized by JavaBean, JavaDao, Service, Spring and so on.

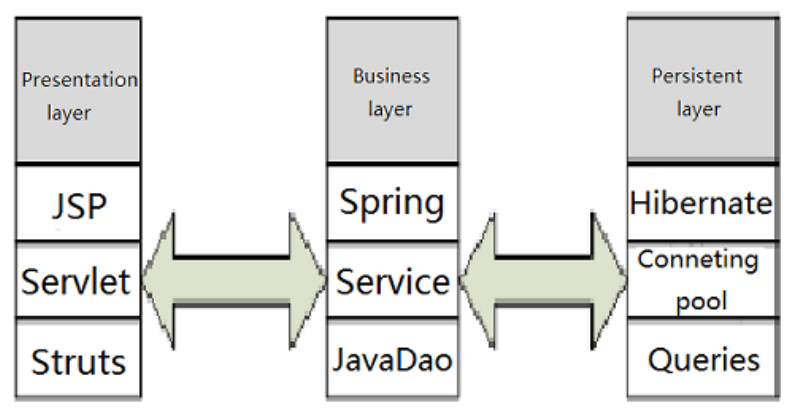

Figure 5. College logistics repair platform program frame
Using MySQL open source database system to build database, including maintenance orders, system users, groups, resources, venues, roles and other 10 entities, a total of 13 data tables, the system ER model is shown in Figure 6.

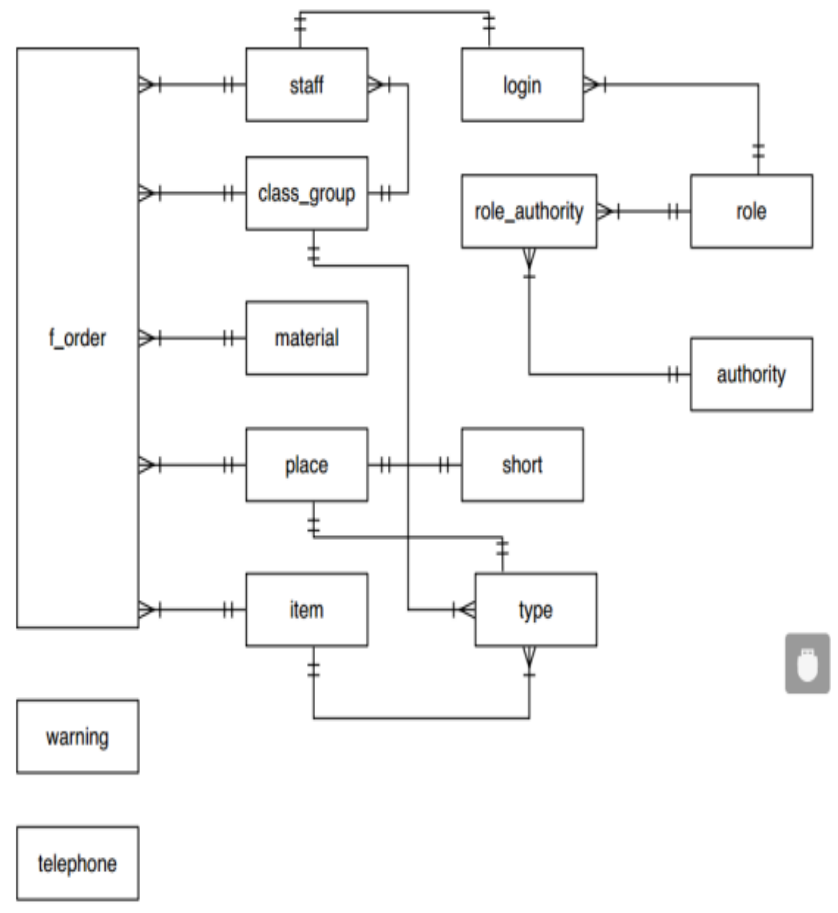

Figure 6. College Logistics repair platform ER

For coherence, using the tone and layout style of the school's other business systems, and the whole system is designed with simple structure.

- Repair business realization

Repair business is the core and foundation of the whole system, Students sign-in repair platform through the authentication, then initiate repair application, system generates repair work orders after the submission and register the work order in the responsible team. The whole repair process is completed. The realization of the whole module can be expressed by the time sequence diagram shown in Figure 7. 


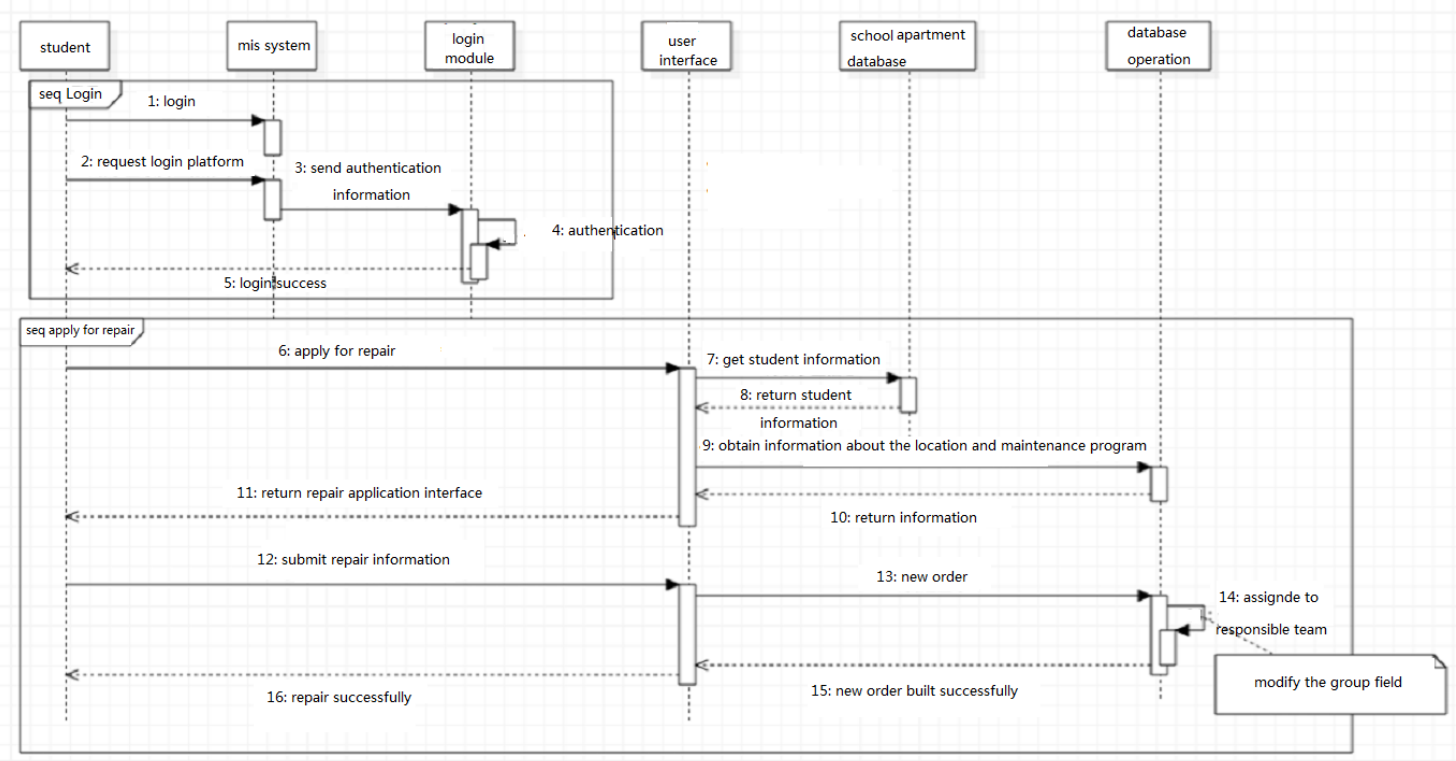

Figure 7. Repair business sequence diagram

Repair application module's ultimate effect as shown in Figure 8.

\section{Applay for repair}

*Note:Current version of this plartform is in the test phase, you can click here to call for repair

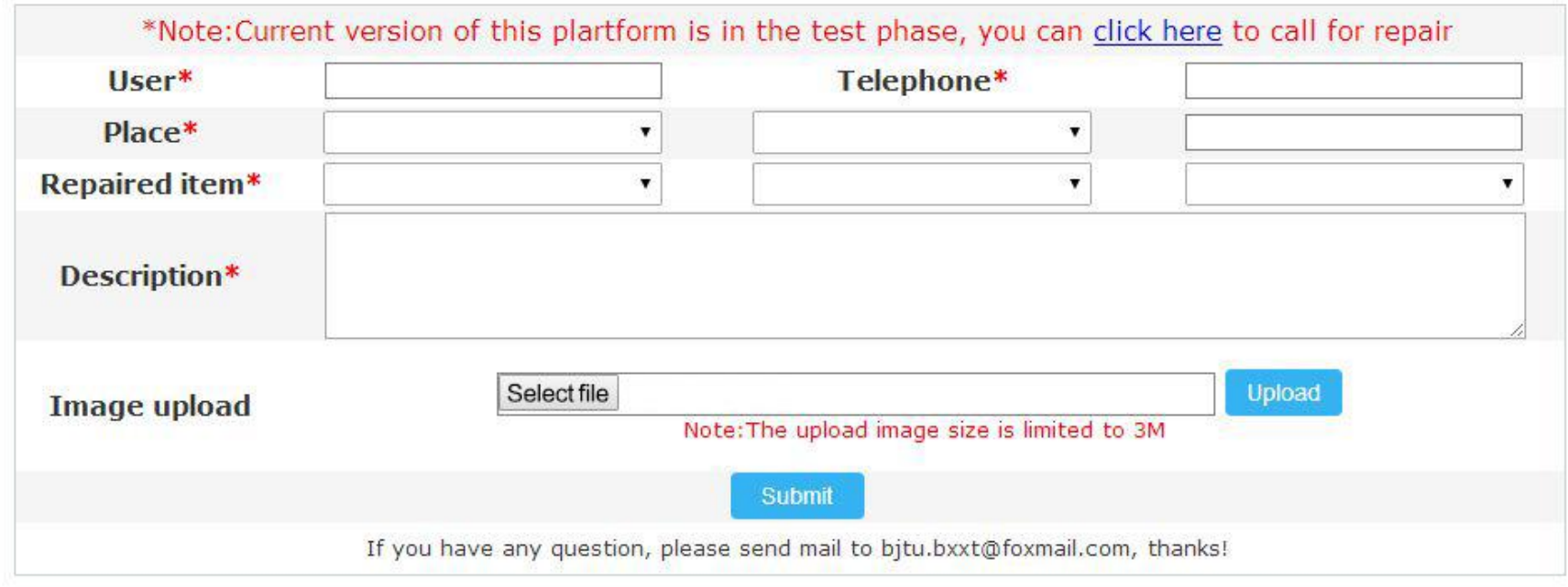

Figure 8. Repair application module's ultimate interface

\section{- Realization of working order's processing}

When the user submits the application, then the system needs to dispatch. The business is mainly performed by the maintenance team. After the person in charge through the authentication login system, firstly get the team's work orders, according to the maintenance requirements of the work order, arrange the corresponding maintenance personnel out of the work, the business "dispatch" is completed. At the same time, the system needs to modify the execution state of the work order and the state of the maintenance personnel. When the maintenance personnel complete the maintenance work and report to the team responsible person, the person in charge modify the execution state of the work order and the state of the maintenance personnel, the business "completion" is done. The realization of this module can be expressed by the time sequence diagram shown in Figure 9 


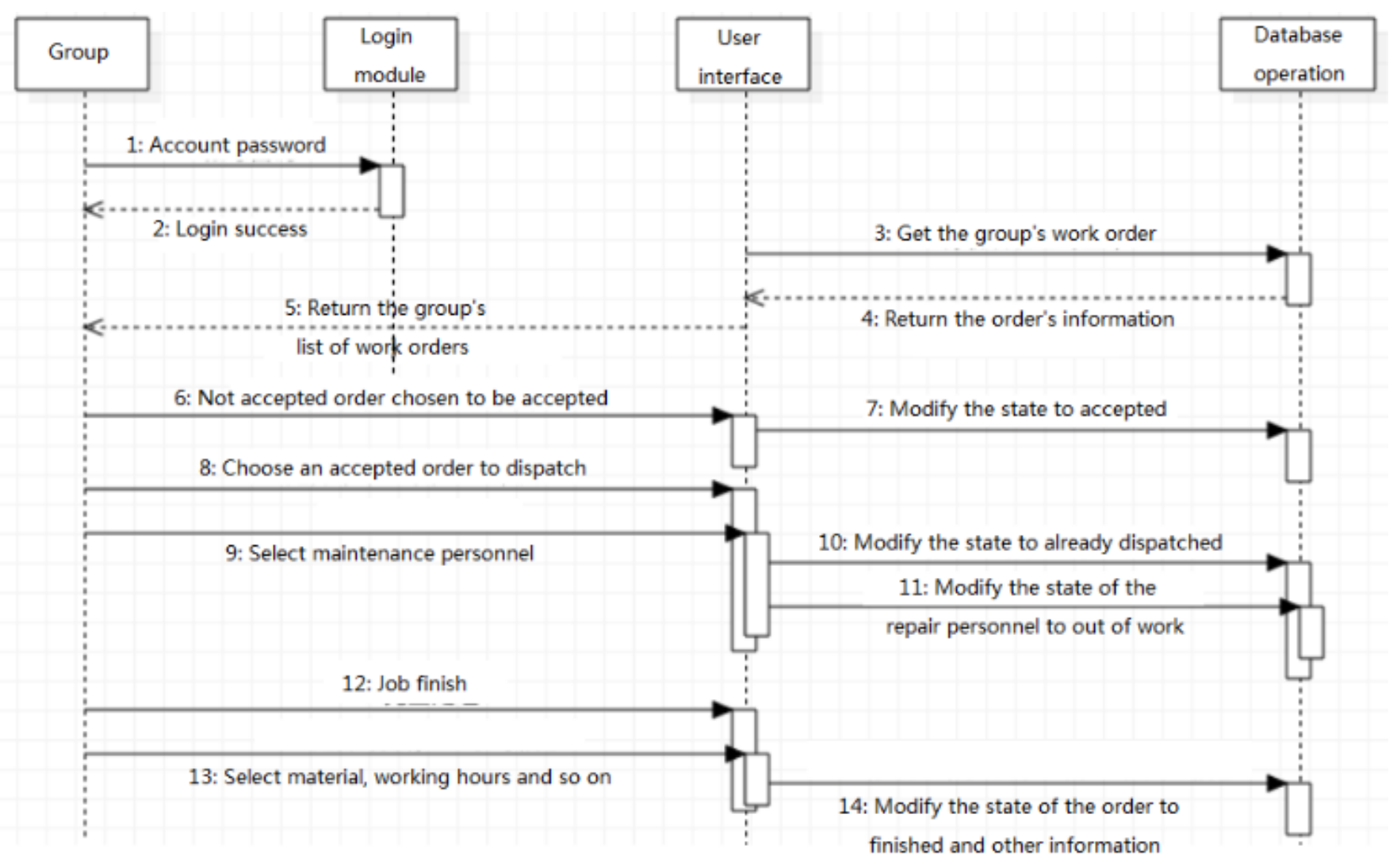

Figure 9. Working order's processing

\section{CONCLUSION}

Repair business, as an important basis for college logistics business, its information construction involves a wide range of users, resource coordination complex, the construction of a stable, efficient and easy to use repair management system is one of the most important challenges of the logistics department. The college logistics repair platform discussed in this paper, in the aspects of construction principles, design idea, development framework are for the construction of other enterprise level repair system has certain guidance and reference significance.

\section{ACKNOWLEDGMENT}

This work is supported by the Beijing Higher Education Young Elite Teacher Project (project No. YETP0548), the Fundamental Research Funds for the Central Universities (project No.2014JBM030). The authors are grateful for the anonymous reviewers who made constructive comments.

\section{REFERENCES}

[1] Ren Bing, The development and application of office automation equipment repair management system. Computer CD software and Application, 2014(4): 144-145.

[2] Zhou Xiang, Design and implementation of university logistics repair system based on Web. Science Mosaic, 2009(11):131-133.

[3] Zhuang ZhenWei, Application of network maintenance management system in logistics management in Colleges. Journal of Juamjusi Education Institute, 2011(5):155-156. G. Eason, B. Noble, and I. N. Sneddon, "On certain integrals of Lipschitz-Hankel type involving products of Bessel functions," Phil. Trans. Roy. Soc. London, vol. A247, pp. 529-551, April 1955. 